University of New Orleans

ScholarWorks@UNO

9-15-1982

\title{
Polarization-preserving single-layer-coated beam displacers and axicons
}

\author{
R. M.A. Azzam \\ University of New Orleans, razzam@uno.edu \\ M. Emdadur Rahman Khan
}

Follow this and additional works at: https://scholarworks.uno.edu/ee_facpubs

Part of the Electrical and Electronics Commons, and the Optics Commons

\section{Recommended Citation}

R. M. A. Azzam and M. Emdadur Rahman Khan, "Polarization-preserving single-layer-coated beam displacers and axicons," Appl. Opt. 21, 3314-3322 (1982)

This Article is brought to you for free and open access by the Department of Electrical Engineering at ScholarWorks@UNO. It has been accepted for inclusion in Electrical Engineering Faculty Publications by an authorized administrator of ScholarWorks@UNO. For more information, please contact scholarworks@uno.edu. 


\title{
Polarization-preserving single-layer-coated beam displacers and axicons
}

\author{
R. M. A. Azzam and M. Emdadur Rahman Khan
}

\begin{abstract}
A design procedure is described to determine the thicknesses of single-layer coatings of a given dielectric on a given metallic substrate so that any input polarization of light is preserved after two reflections at the same angle of incidence from a parallel-mirror beam displacer or an axicon. This is achieved by equalizing the net complex $p$ and $s$ reflection coefficients (also called the radial and azimuthal eigenvalues of an axicon) after two reflections. The net polarization-independent reflectance (insertion loss) of the device is computed and found to exceed the net minimum parallel reflectance of the uncoated device for incidence above a certain angle. Thus the dielectric films serve (1) protective, (2) polarization-corrective, and (3) reflectanceenhancement functions simultaneously. The sensitivity of the designs (deviation from the condition of polarization preservation) to small film-thickness and angle-of-incidence errors is examined. Results are presented graphically and in tables of applications of the method to beam displacers and axicons for $\mathrm{He}-\mathrm{Ne}$ laser light, $\lambda=0.6328 \mu \mathrm{m}$, using $\mathrm{Al}_{2} \mathrm{O}_{3}$ (or $\mathrm{Si}_{2} \mathrm{O}_{3}$ )/ $\mathrm{Al}$ and $\mathrm{MgF}_{2} / \mathrm{Al}$ film-substrate systems, and for $\mathrm{CO}_{2}$ laser light, $\lambda=10.6 \mu \mathrm{m}$, using $\mathrm{ZnS}$ or $\mathrm{ThF}_{4}$ films on an $\mathrm{Ag}$ substrate.
\end{abstract}

\section{Introduction}

In a recent Letter, ${ }^{1}$ it was shown that it is possible to displace a monochromatic light beam parallel to itself without change of polarization by a pair of parallel mirrors, if the metallic mirror surfaces are coated by a single dielectric layer of specific thickness for each mirror. The idea is to accept the polarization change that accompanies a single reflection but to make the polarization changes upon two consecutive reflections mutually compensating for a net null effect. This simple approach can be directly applied to the design of polarization-preserving axicon reflectors for lasers with an annular gain region. ${ }^{2-4}$ The polarization problem of such biconical laser mirrors had earlier been stated by Fink ${ }^{5}$, and, shortly thereafter, a solution was provided by Southwell ${ }^{6}$ using $90^{\circ} /$ reflection multilayer phase-shift coatings.

In this paper we describe the design procedure of polarization-preserving single-layer-coated beam displacers and axicons (Fig. 1) and present detailed results of its application, including an error analysis, over the

The authors are with University of New Orleans, Department of Electrical Engineering, Lakefront, New Orleans, Louisiana 70148. Received 21 May 1982.

0003-6935/82/183314-09\$01.00/0.

(C) 1982 Optical Society of America. full range of angles of incidence $0<\phi<90^{\circ}$, using dielectric-coated aluminum and silver mirrors at the common $0.6328-\mu \mathrm{m} \mathrm{He}-\mathrm{Ne}$ and $10.6-\mu \mathrm{m} \mathrm{CO} \mathrm{CO}_{2}$ laser wavelengths.

\section{Design Procedure}

The change of polarization on single reflection from an optically isotropic surface is completely determined by the ratio of complex reflection coefficients,

$$
\rho=R_{p} / R_{s}
$$

of the parallel $p$ and perpendicular $s$ polarizations. For light of wavelength $\lambda$, incident at an angle $\phi$ from a transparent ambient of refractive index $N_{0}$ onto a metallic substrate coated by a dielectric film of thickness $d$ and refractive index $N_{1}$, the $p$ and $s$ reflection coefficients are given by ${ }^{7}$

$$
R_{\nu}=\frac{r_{01 \nu}+r_{12 \nu} \exp (-j 2 \pi \zeta)}{1+r_{01 \nu} r_{12 \nu} \exp (-j 2 \pi \zeta)}, \quad \nu=p, \mathrm{~s}
$$

$r_{01 \nu}$ and $r_{12 \nu}$ are the ambient-film and film-substrate Fresnel's interface reflection coefficients for the $\nu$ polarization, and $\zeta$ is the normalized film thickness:

$$
\zeta=d / D_{\phi},
$$

where

$$
D_{\phi}=\frac{\lambda}{2}\left(N_{1}^{2}-N_{0}^{2} \sin ^{2} \phi\right)^{-1 / 2}
$$

is the film-thickness period. From Eqs. (1) and (2) it is evident that $\rho$ is a function of $\phi$ and $\zeta$; 


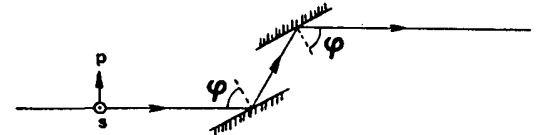

(a)

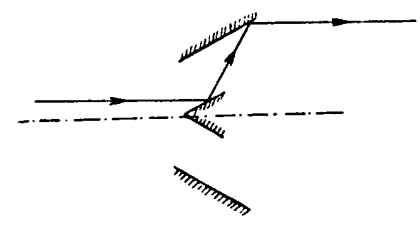

$|b|$

Fig. 1. (a) Parallel-mirror beam displacer; (b) axial cross section of an axicon.

$$
\rho=f(\phi, \zeta)
$$

If two parallel mirrors (of a beam displacer) or coaxial cones (of an axicon reflector) of the same substrate material are coated by a transparent film of the same dielectric material but of thickness $\zeta_{1}$ for one mirror and $\zeta_{2}$ for the other, the combined effect of two reflections at the same angle $\phi$ is given by the product

$$
\rho_{n}=\rho_{1} \rho_{2}=f\left(\phi, \zeta_{1}\right) f\left(\phi, \zeta_{2}\right) \text {. }
$$

The condition of preservation of polarization is that

$$
\rho_{n}=1
$$

or that

$$
f\left(\phi, \zeta_{1}\right)=g\left(\phi, \zeta_{2}\right)
$$

where

$$
g(\phi, \zeta)=1 / f(\phi, \zeta)
$$

Equation (8) can be solved for $\zeta_{1}, \zeta_{2}$ (for a given $\phi$ ) numerically on a digital computer. To this end, we have used the following Newton-Raphson method. ${ }^{8}$ Equation (8) is broken into its real and imaginary parts:

$$
\begin{gathered}
f_{r}\left(\phi, \zeta_{1}\right)=g_{r}\left(\phi, \zeta_{2}\right), \\
f_{i}\left(\phi, \zeta_{1}\right)=g_{i}\left(\phi, \zeta_{2}\right),
\end{gathered}
$$

where

$$
f=f_{r}+j f_{i}, \quad g=g_{r}+j g_{i} .
$$

We look for solutions $\zeta_{1}, \zeta_{2}$ of Eqs. (10) in the reduced thickness range:

$$
0 \leq \zeta_{1,2}<1 .
$$

An arbitrary initial trial solution $\left(\zeta_{1}^{0}, \zeta_{2}^{0}\right)$ is assumed that will not, of course, satisfy Eqs. (10). To move closer to the correct solution, this initial vector is incremented by $\left(\Delta \zeta_{1}, \Delta \zeta_{2}\right)$. The new vector $\left(\zeta_{1}^{0}+\Delta \zeta_{1}, \zeta_{2}^{0}, \Delta \zeta_{2}\right)$ is then required to satisfy Eqs. (10):

$$
\begin{aligned}
& f_{r}\left(\zeta_{1}^{0}+\Delta \zeta_{1}\right)=g_{r}\left(\zeta_{2}^{0}+\Delta \zeta_{2}\right), \\
& f_{i}\left(\zeta_{1}^{0}+\Delta \zeta_{1}\right)=g_{i}\left(\zeta_{2}^{0}+\Delta \zeta_{2}\right),
\end{aligned}
$$

where the argument $\phi$ of all functions has been dropped for simplicity. We pretend that the initial vector is sufficiently close to the correct solution to justify a linear two-term Taylor-series expansion of Eqs. (13); this gives

$$
\begin{gathered}
f_{r}^{\prime}\left(\zeta_{1}^{0}\right) \Delta \zeta_{1}-g_{r}^{\prime}\left(\zeta_{2}^{0}\right) \Delta \zeta_{2}=g_{r}\left(\zeta_{2}^{0}\right)-f_{r}\left(\zeta_{1}^{0}\right), \\
f_{i}^{\prime}\left(\zeta_{1}^{0}\right) \Delta \zeta_{1}-g_{i}^{\prime}\left(\zeta_{2}^{0}\right) \Delta \zeta_{2}=g_{i}\left(\zeta_{2}^{0}\right)-f_{i}\left(\zeta_{1}^{0}\right) .
\end{gathered}
$$

In Eqs. (14) the prime superscript indicates the first partial derivative with respect to $\zeta$ (i.e., $f_{r}^{\prime}=\partial f_{r} / \partial \zeta$ etc.). Such derivatives can be obtained from Eqs. (1) and (2) as follows:

$$
\begin{aligned}
f^{\prime}=\rho^{\prime} & =\left(R_{p}^{\prime} / R_{s}\right)-\left(R_{p} R_{s}^{\prime} / R_{s}^{2}\right), \\
R_{\nu}^{\prime} & =-j 2 \pi \exp (-j 2 \pi \zeta) \frac{r_{12 \nu}\left(1-r_{01 \nu}^{2}\right)}{\left[1+r_{01 \nu} r_{12 \nu} \exp (-j 2 \pi \zeta)\right]^{2}}, \nu=p, s, \\
g^{\prime} & =-f^{\prime} / f^{2}, \\
f_{r}^{\prime} & =\operatorname{Re} f^{\prime} f_{i}^{\prime}=\operatorname{Im} f^{\prime} ; g_{r}^{\prime}=\operatorname{Reg}^{\prime}, g_{i}^{\prime}=\operatorname{Img} g^{\prime} .
\end{aligned}
$$

The two linear algebraic equations (14) are solved for $\Delta \zeta_{1}, \Delta \zeta_{2}$. The new vector $\left(\zeta_{1}^{0}+\Delta \zeta_{1}, \zeta_{2}^{0}+\Delta \zeta_{2}\right)$ is determined and is used as an updated (improved) initial vector for the second round of iteration. This process is repeated until the change of $\Delta \zeta_{1}, \Delta \zeta_{2}$ between the $n$ +1 and $n$ iteration steps falls below $10^{-6}$ or $10^{-7}$, at which point the solution is considered reached. As a check, the final solution vector $\left(\zeta_{1}, \zeta_{2}\right)$ is substituted into the right-hand side of Eq. (6), and the net ratio of reflection coefficients $\rho_{n}$ is verified to be unity to within $10^{-6}$ in the real and imaginary parts. Hence polarization preservation is achieved.

We have found the foregoing simple Newton-Raphson method to be adequate and accurate and converges, after a reasonable number of iterations (usually <30), to a correct solution when an arbitrary initial vector $\left(\zeta_{1}, \zeta_{2}\right)$ is assumed. Furthermore, all valid multiple solutions (when they exist) can be uniquely determined by beginning iteration from a sufficiently large number of different initial vectors. To verify the number of solutions, we have on occasion plotted the closed contours of $\rho$ and $1 / \rho$ at a given $\phi$ and checked and counted their points of intersection.

It should be noted that if $\left(\zeta_{1}, \zeta_{2}\right)$ is a solution, $\left(\zeta_{1}+m\right.$, $\zeta_{2}+n$ ) will also be a solution, where $m$ and $n$ are any two positive integers. This follows because the $p$ and $s$ reflection coefficients, Eq. (2), hence their ratio $\rho$, are periodic functions of $\zeta$ of period 1. The actual thicknesses of the dielectric films are given by

$$
\left(d_{1}, d_{2}\right)=\left(\zeta_{1} D_{\phi}, \zeta_{2} D_{\phi}\right)
$$

As we stated earlier, we will consider only the reduced (least) film thickness in the interval specified by (12), the periodic multiplicity of the solutions being understood.

In addition to the polarization-maintaining characteristic of the beam displacers and axicons that are designed as described here, such devices have the important advantage of a net reflectance (insertion loss) that is independent of the input polarization. (The net reflectance of the uncoated device is, of course, a function 


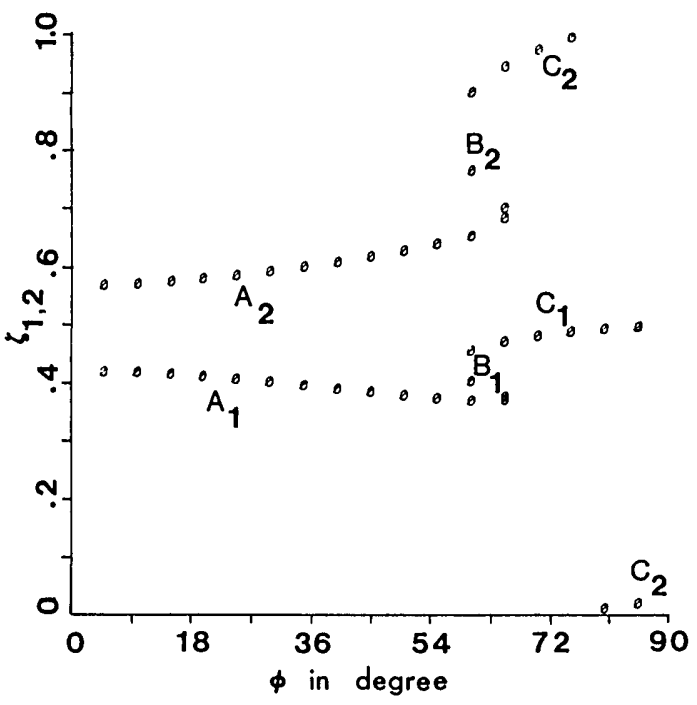

Fig. 2. Normalized film-thickness solution pairs $\left(\zeta_{1}, \zeta_{2}\right)$ that preserve polarization are plotted vs angle of incidence $\phi$ for $\mathrm{Al}_{2} \mathrm{O}_{3}$ (or $\mathrm{Si}_{2} \mathrm{O}_{3}$ )/Al beam displacers and axicons at $\lambda=0.6328 \mu \mathrm{m}$. $\phi$ is incremented from 5 to $85^{\circ}$ in discrete steps of $5^{\circ}$. The refractive indices of $\mathrm{Al}_{2} \mathrm{O}_{3}$ (or $\mathrm{Si}_{2} \mathrm{O}_{3}$ ) and of $\mathrm{Al}$ are taken to be 1.55 and $1.212-j 6.924$, respectively.

of the input polarization.) The polarization-independent net intensity reflectance of the coated device,

$$
\mathscr{R}_{c}=\mathscr{R}_{p}=\mathscr{R}_{s},
$$

is calculated from Eq. (2) as

$$
\mathcal{R}_{c}=\left|R_{\nu}\right|^{4}, \quad \nu=p \text { or } s .
$$

Equality of the net (two-bounce) reflectance for the $p$ and $s$ polarization, Eq. (20), provides an additional check on the correctness of the solutions obtained.

In the following we will also examine the sensitivity of a given design to small film-thickness and angleof-incidence errors. This is done by direct calculation of the perturbed net ratio of the reflection coefficients $\rho_{n}$ :

$$
\rho_{n}=\rho_{1}\left(\zeta_{1}, \phi_{1}\right) \rho_{2}\left(\zeta_{2}, \phi_{2}\right)
$$

where

$$
\zeta_{i}=\zeta_{i}+\Delta \zeta_{i}, \quad \phi_{i}=\phi_{i}+\Delta \phi_{i}, i=1,2 .
$$

$\left(\zeta_{1}, \zeta_{2}\right)$ is an exact solution (film-thickness pair) at a given angle of incidence $\phi_{1}=\phi_{2}=\phi$, and $\Delta \zeta_{i}, \Delta \phi_{i}$ are intentional and independent small film-thickness and angle-of-incidence errors. The deviation from the ideal condition of polarization preservation, $\rho_{n}=1$, is expressed in terms of separate magnitude and phase errors:

$$
\begin{aligned}
\text { magnitude error } & =\left|\rho_{n}\right|-1, \\
\text { phase error } \Delta_{n} & =\arg \rho_{n} .
\end{aligned}
$$

The wavelength sensitivity of a design can be estimated from its film-thickness sensitivity, if the effect of material dispersion over the narrow spectral width of the source is neglected. In this case, a wavelength shift $\Delta \lambda$ has the same effect as simultaneous filmthickness errors $\Delta d_{i}$ where $\Delta d_{i} / d_{i}=-\Delta \lambda / \lambda$, and $i=1,2$ for mirrors 1 and 2 .

\section{Polarization-Preserving Beam Displacers and Axicons at $\lambda=0.6328 \mu \mathrm{m}$}

\section{A. $\mathrm{Al}_{2} \mathrm{O}_{3}$ (or $\mathrm{Si}_{2} \mathrm{O}_{3}$ ) Film on $\mathrm{Al}$ substrate}

As a first design example, we consider parallel-mirror beam displacers or axicons that preserve polarization of $\mathrm{He}-\mathrm{Ne}$ laser light of $0.6328-\mu \mathrm{m}$ wavelength. We assume incidence from a medium of refractive index $N_{0}$ $=1$ (usually air), take aluminum as a substrate (usually obtained by vacuum deposition of an optically thick opaque layer of the metal), and assume a transparent film of refractive index 1.55, which represents either $\mathrm{Al}_{2} \mathrm{O}_{3}$ (simply obtained by oxidation of the $\mathrm{Al}$ substrate) or $\mathrm{Si}_{2} \mathrm{O}_{3}$ (obtained by vacuum deposition of $\mathrm{SiO}$ in the presence of oxygen). ${ }^{9}$. It is interesting to note that such layers are often used anyway as protective layers, and it is indeed worthwhile to require that they also serve the additional function of polarization preservation in beam displacer or axicon applications by properly selecting their thicknesses. The complex refractive index of $\mathrm{Al}$ is taken as ${ }^{10} 1.212-j 6.924$. Because the optical properties of materials depend on conditions of their preparation $^{11}$ (especially if that involves vacuum evaporation), only values that are truely representative of a given actual process should be used in the design.

The design procedure of Sec. II was applied at discrete angles of incidence $\phi$ from 5 to $85^{\circ}$ in steps of $5^{\circ}$. Solutions for the normalized film-thickness pair $\left(\zeta_{1}, \zeta_{2}\right)$ were found at all angles and are plotted vs $\phi$ in Fig. 2 . Multiple (three) solutions per angle of incidence exist over a certain range of $\phi$. To clarify this, the curves of $\zeta_{1}$ and $\zeta_{2}$ vs $\phi$ are broken into three distinct solution branches indicated by $A, B, C$, and the region of multiple solutions of Fig. $2,57^{\circ} \lesssim \phi \lesssim 65^{\circ}$, is magnified and plotted separately in Fig. 3.

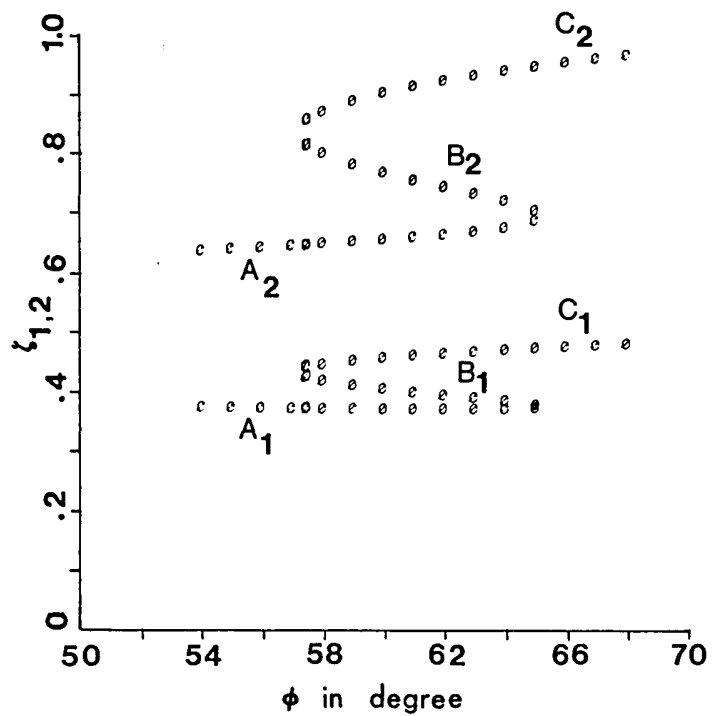

Fig. 3. Expansion of the region of multiple solutions $57^{\circ} \lesssim \phi \lesssim 65^{\circ}$ of Fig. 2. 


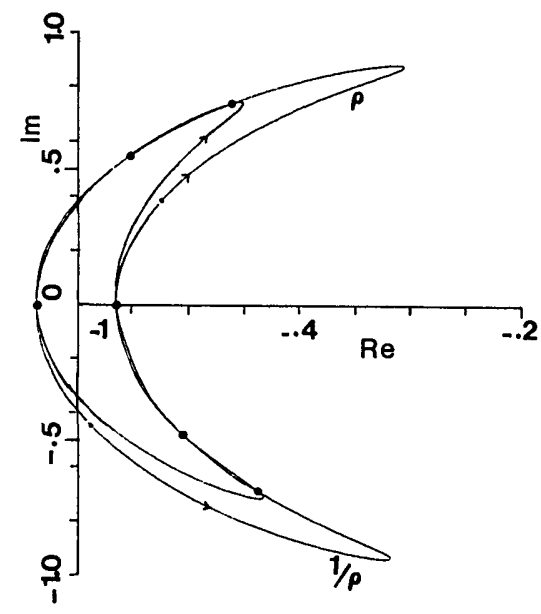

(a)

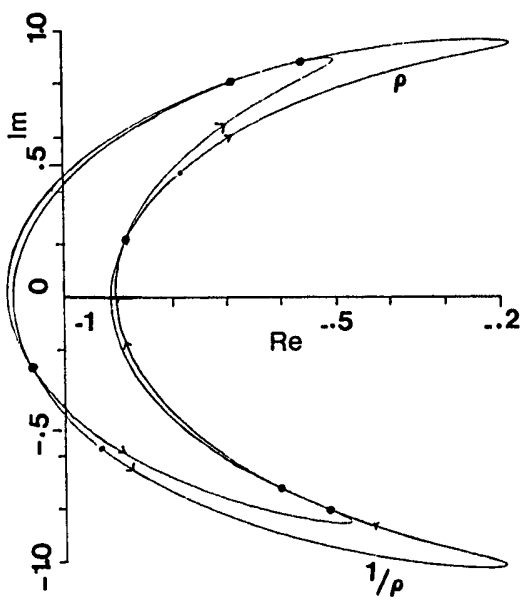

(b)

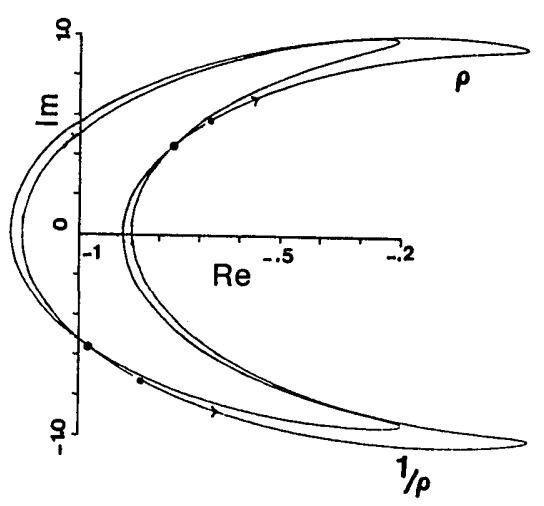

(c)

Fig. 4. Intersection of the closed contours of the ratio of $p$ and $s$ reflection coefficients $\rho$ and its inverse $1 / \rho$ in the complex plane for three angles of incidence: (a) $\phi_{1}=60^{\circ}$; (b) $\phi_{2}=65^{\circ}$; and (c) $\phi_{3}=70^{\circ}$. The number of distinct normalized film-thickness solutions $\left(\zeta_{1}, \zeta_{2}\right)$ equals one half of the number of points of intersection of the $\rho$ and $1 / \rho$ curves. A dielectric $\mathrm{Al}_{2} \mathrm{O}_{3}$ or $\mathrm{Si}_{2} \mathrm{O}_{3}$ film of refractive index 1.55 on aluminum $(N=1.212-j 6.924)$ is assumed at $\lambda=0.6328 \mu \mathrm{m}$.
For further illustration, Fig. 4 shows the intersection of the closed contours of $\rho$ and $1 / \rho$ in the complex plane at three angles of incidence $\phi_{1}=60^{\circ}, \phi_{2}=65^{\circ}$, and $\phi_{3}$ $=70^{\circ}$. For clarity, these figures are stretched in the horizontal real-axis direction by a constant scaling factor. The number of distinct solutions $\left(\zeta_{1}, \zeta_{2}\right)$ for polarization preservation is equal to one half of the number of points of intersection of the $\rho$ and $1 / \rho$ curves. [Each solution $\left(\zeta_{1}, \zeta_{2}\right)$ has a physically indistinguishable associated solution obtained by interchanging $\zeta_{1}$ and $\zeta_{2}$.] Six points of intersection, corresponding to three solutions, appear for $\phi_{1}=60^{\circ}$, which lies within the range of multiple solutions in Figs. 2 and 3. For $\phi_{3}=$ $70^{\circ}$, the $\rho$ and $1 / \rho$ contours interesect at two points. Hence they provide one solution belonging to branch $C$ of Figs. 2 and 3. The case of $\phi_{2}=65^{\circ}$ represents sufficiently closely the limiting case when two of the three solutions coincide at the boundary between the regions of one and three solutions. At $\phi=65^{\circ}$ six points of intersection, hence three solutions, are discernible.

In Fig. 2 the apparent down-jump of $\zeta_{2}$ of branch $C_{2}$, when $\phi$ increases from 75 to $80^{\circ}$, is not a true discontinuity because it takes place as $\zeta_{2}$ goes through unity, which is indistinguishable from zero. It is merely an artifact resulting from limiting $\zeta$ to the reduced thickness range of Eq. (12).

In Fig. 5, curve $c$ shows the net (two-bounce) polarization-independent intensity reflectance vs $\phi$ of the polarization-preserving designs of Fig. 2. Superimposed on Fig. 5 are curves $p$ and $s$ for the net reflectances of the corresponding uncoated (bare-substrate) devices for the parallel $p$ and perpendicular $s$ polarizations. Notice that for $0<\phi \lesssim 57^{\circ}$, the net reflectance of the

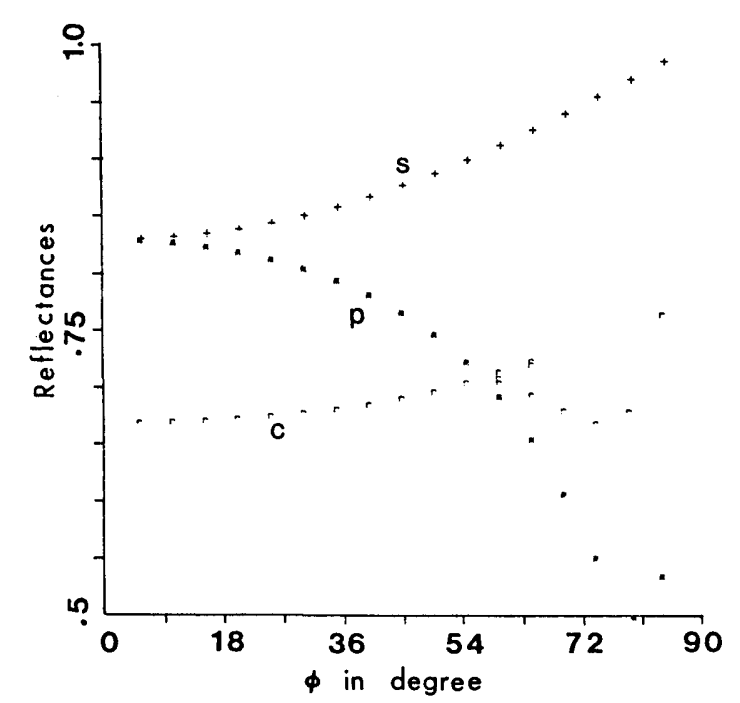

Fig. 5. Reflectances associated with the designs of Fig. 2. Curve $c$ represents the net polarization-independent reflectance of the coated (polarization-corrected) device, while curves $p$ and $s$ represent the reflectances of the corresponding uncoated devices for incident parallel- and perpendicularly polarized light, respectively. 
Table I. Summary of Design Results for $\mathrm{Al}_{2} \mathrm{O}_{3}$ (or $\mathrm{Si}_{2} \mathrm{O}_{3}$ )/Al PolarizationPreserving Beam Displacers and Axicons at Three Angles of Incidence

\begin{tabular}{|c|c|c|c|c|c|c|c|}
\hline $\begin{array}{c}\phi \\
\text { (deg) }\end{array}$ & & $\zeta_{1}$ & $\zeta_{2}$ & $D_{\phi}$ & $\overline{\mathcal{R}}_{p}$ & $\overline{\mathcal{R}}_{s}$ & $\mathcal{R}_{c}$ \\
\hline 30 & & 0.403999 & 0.594216 & 0.21565 & 0.8006 & 0.8468 & 0.6763 \\
\hline \multirow[t]{3}{*}{45} & & 0.386571 & 0.619742 & 0.22932 & 0.7627 & 0.8733 & 0.6894 \\
\hline & & 0.372229 & 0.65636 & 0.24612 & 0.6896 & 0.9089 & 0.7130 \\
\hline & & 0.405610 & 0.767628 & 0.24612 & 0.6896 & 0.9089 & 0.7076 \\
\hline 60 & $C$ & 0.458161 & 0.902621 & 0.24612 & 0.6896 & 0.9089 & 0.7035 \\
\hline
\end{tabular}

$\phi$ is the angle of incidence in degrees; $\left(\zeta_{1}, \zeta_{2}\right)$ is the normalized film-thickness solution pair; $D_{\phi}$ is the film-thickness period in microns; $\overline{\mathscr{R}}_{p}, \overline{\mathscr{R}}_{s}$ are the net reflectances of the uncoated device for the $p$ and $s$ polarizations; and $\mathscr{R}_{c}$ is the net reflectance of the coated (polarization-corrected) device.

Table II. Magnitude and Phase Errors Caused by Introducing (I) FilmThickness Errors $\left(\Delta d_{1}, \Delta d_{2}\right)=(+1, \pm 1) \mathrm{nm}$, (II) Angle-of-Incidence Errors $\left(\Delta \phi_{1}, \Delta \phi_{2}\right)=\left(+0.5, \pm 0.5^{\circ}\right)$ to the Beam Displacer and Axicon Designs of Table I

\begin{tabular}{|c|c|c|c|c|c|}
\hline \multirow{2}{*}{$\begin{array}{l}\text { Error } \\
\text { type }\end{array}$} & \multirow{2}{*}{$\begin{array}{c}\text { Angle of } \\
\text { incidence } \\
(\phi) \\
(\mathrm{deg})\end{array}$} & \multicolumn{2}{|c|}{$\begin{array}{l}\text { Magnitude error } \\
\left(\left|\rho_{n}\right|-1\right) \times 10^{4}\end{array}$} & \multicolumn{2}{|c|}{$\begin{array}{c}\text { Phase error } \\
\left(\Delta_{n}\right)(\mathrm{deg})\end{array}$} \\
\hline & &,+- &,++ &,+- &,++ \\
\hline \multirow[t]{5}{*}{ I } & 30 & 7.717 & -0.6488 & 0.3349 & 0.5126 \\
\hline & 45 & 20.35 & 3.41 & 0.8871 & 0.9740 \\
\hline & $A$ & 42.19 & 17.63 & 1.8600 & 1.3343 \\
\hline & $B$ & 27.02 & 16.68 & 2.9275 & 1.3713 \\
\hline & $60 \bar{C}$ & -10.69 & -12.34 & 3.3389 & 1.3617 \\
\hline \multirow[t]{5}{*}{ II } & 30 & 4.533 & 1.131 & -0.5056 & 0.3790 \\
\hline & 45 & 9.996 & 3.608 & -1.09 & 0.1117 \\
\hline & $A$ & 31.95 & 7.492 & -1.5111 & 0.2194 \\
\hline & $B$ & 17.32 & 7.22 & -2.2037 & 0.2136 \\
\hline & $60 \mathrm{C}$ & 42.05 & 7.492 & 0.1109 & 0.2287 \\
\hline
\end{tabular}

coated (polarization-corrected) device $\mathscr{R}_{c}$ is less than both the $p$ and $s$ reflectances, $\overline{\mathscr{R}}_{p}$ and $\overline{\mathscr{R}}_{s}$, of the uncoated device, i.e.,

$$
\mathcal{R}_{c}<\overline{\mathscr{R}}_{p}<\overline{\mathscr{R}}_{s} .
$$

Thus polarization preservation by thin-film coatings is achieved at the expense of a loss of several percent of reflectance. However, for $\phi \gtrsim 57^{\circ}, R_{c}$ lies between the minimum $p$ and maximum $s$ reflectances of the uncoated device

$$
\overline{\mathcal{R}}_{p}<\mathcal{R}_{c}<\overline{\mathcal{R}}_{s} .
$$

It is interesting to note that $\phi \approx 57^{\circ}$ marks the onset of the region of multiple solutions (see Figs. 2 and 3 ). According to Fig. 5 and (24b), it is therefore significant to observe that thin-film coatings that preserve polarization (at $\phi \gtrsim 57^{\circ}$ ) also enhance the net reflectance of the device above its minimum value for the $p$ polarization in the absence of films. Another noteworthy feature of Fig. 5 is that $\mathcal{R}_{c}$ goes through a shallow minimum, which is obviously correlated to the minimum of $\overline{\mathscr{R}}_{p}$ at the pseudo-Brewster angle, $\phi_{\mathrm{pB}} \approx 81^{\circ}$.

Table I lists a summary of the design results of $\mathrm{Al}_{2} \mathrm{O}_{3}$ (or $\mathrm{Si}_{2} \mathrm{O}_{3}$ )-on-Al polarization-preserving beam displacers and axicons that operate at wavelength $\lambda=$ $0.6328 \mu \mathrm{m}$ for three angles of incidence of 30,45 , and $60^{\circ}$. The table includes the normalized film-thickness solution pairs $\left(\zeta_{1}, \zeta_{2}\right)$, film-thickness period $D_{\phi}$, the $p$ and $s$ reflectances of the uncoated device $\overline{\mathscr{R}}_{p}$ and $\overline{\mathscr{R}}_{s}$, and the net reflectance of the device with the polarization-corrective coatings $\mathcal{R}_{c}$. In all cases the net ratio of complex $p$ and $s$ reflection coefficients $\rho_{n}$ differs from 1 by $<10^{-6}$ or $10^{-7}$ in real and imaginary parts.

Because small errors of film thickness and angle of incidence are inevitable, we consider their effect on the device performance. Specifically, we determine the resulting deviation from the condition of polarization preservation, $\rho_{n}=1$, expressed as a magnitude error, $\left|\rho_{n}\right|-1$, and a phase error $\Delta_{n}$.

Table II summarizes the magnitude $\left(\left|\rho_{n}\right|-1\right)$ and phase $\left(\Delta_{n}\right)$ errors generated by $(+1-\mathrm{nm}, \pm 1-\mathrm{nm})$ thickness errors and $\left(+0.5, \pm 0.5^{\circ}\right)$ angle-of-incidence errors for the same 30,45 , and $60^{\circ}$ designs that are given in Table I.

Partial derivatives can be readily deduced from Table II by noting, e.g., for thickness-related phase errors, that

$$
\Delta_{n}=\frac{\partial \Delta_{n}}{\partial d_{1}} \Delta d_{1}+\frac{\partial \Delta_{n}}{\partial d_{2}} \Delta d_{2}
$$

to first order, so that

$$
\begin{aligned}
& \Delta_{n}^{++}=\left(\frac{\partial \Delta_{n}}{\partial d_{1}}+\frac{\partial \Delta_{n}}{\partial d_{2}}\right) \times 1 \mathrm{~nm}, \\
& \Delta_{n}^{+-}=\left(\frac{\partial \Delta_{n}}{\partial d_{1}}-\frac{\partial \Delta_{n}}{\partial d_{2}}\right) \times 1 \mathrm{~nm} .
\end{aligned}
$$

From Eqs. (26) we get

$$
\begin{aligned}
& \frac{\partial \Delta_{n}}{\partial d_{1}}=1 / 2\left(\Delta_{n}^{++}+\Delta_{n}^{+-}\right) \operatorname{deg} / \mathrm{nm}, \\
& \frac{\partial \Delta_{n}}{\partial d_{2}}=1 / 2\left(\Delta_{n}^{++}-\Delta_{n}^{+-}\right) \operatorname{deg} / \mathrm{nm} .
\end{aligned}
$$

Similar relations can be written for thickness-related magnitude errors as well as for $\phi$-related phase and magnitude errors.

\section{B. $\mathrm{MgF}_{2}$ Film on Al Substrate}

As a second example, we consider another often-used dielectric coating, namely, magnesium fluoride (refractive index $\left.N_{1}=1.38\right)^{9}$ on an aluminum substrate $\left(N_{2}=1.212-j 6.924\right)$ at $\lambda=0.6328 \mu \mathrm{m}$. Application of the design procedure of Sec. II to this film-substrate system leads to the results shown in Fig. 6. It is interesting to note the drastic change that has resulted from changing the film refractive index from 1.55 (Fig. 2) to 1.38 (Fig. 6). As seen in Fig. 6, only one solution for the normalized film-thickness pair $\left(\zeta_{1}, \zeta_{2}\right)$ per $\phi$ is now possible over a limited range of incidence angles, $34^{\circ} \lesssim$ $\phi<90^{\circ}$. For $\phi \lesssim 34^{\circ}$, no solutions exist, so that polarization-preservation could not be achieved at these angles using this $\mathrm{MgF}_{2} / \mathrm{Al}$ system.

Figure 7 shows the net reflectance $\mathcal{R}_{c}$ of the coated (polarization-corrected) parallel-mirror beam displacer or axicon and the $p$ and $s$ reflectances, $\overline{\mathcal{R}}_{p}$ and $\overline{\mathcal{R}}_{s}$, of the corresponding uncoated (bare-aluminum) device. For angles of incidence $\phi \gtrsim 55^{\circ}$, we have $\mathcal{R}_{c}>\overline{\mathcal{R}}_{p}$, so that the polarization-corrective (also protective) $\mathrm{MgF}_{2}$ films also enhance the reflectance of the device above 


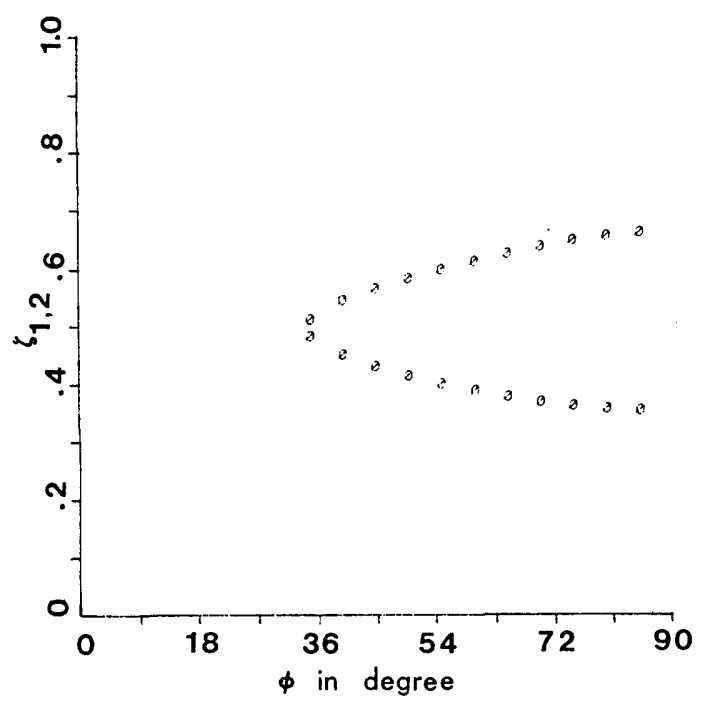

Fig. 6. Normalized film-thickness solution pair $\left(\zeta_{1}, \zeta_{2}\right)$ that preserves polarization plotted vs angle of incidence $\phi$ for $\mathrm{MgF}_{2} / \mathrm{Al}$ beam displacers and axicons at $\lambda=0.6328 \mu \mathrm{m}$. The refractive indices of $\mathrm{MgF}_{2}$ and $\mathrm{Al}$ are assumed to be 1.38 and $1.212-j 6.924$, respectively.

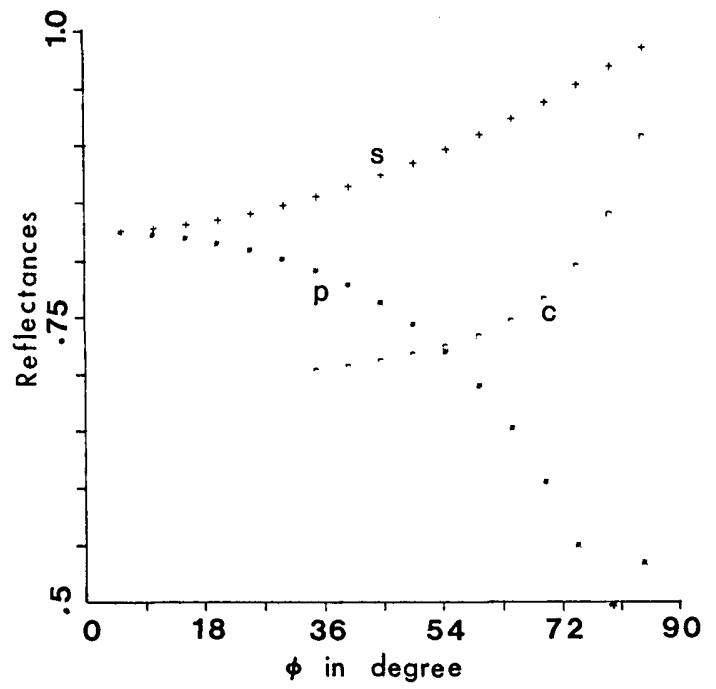

Fig. 7. Reflectances associated with the designs of Fig. 6. Curve $c$ represents the net polarization-independent reflectance of the coated (polarization-corrected) device, while curves $p$ and $s$ represent the reflectances of the corresponding uncoated devices for incident parallel- and perpendicularly polarized light, respectively.

its minimum value for the $p$ polarization in the absence of coatings. In general, the reflectance of the $\mathrm{MgF}_{2} / \mathrm{Al}$ system (Fig. 7) is a few percent higher than that of the $\mathrm{Al}_{2} \mathrm{O}_{3}$ (or $\mathrm{Si}_{2} \mathrm{O}_{3}$ )/Al system (Fig. 5).

Table III provides a summary of design results of polarization-preserving beam displacers and axicons, for three angles $\phi=35,45$, and $60^{\circ}$, using the $\mathrm{MgF}_{2} / \mathrm{Al}$ film-substrate system at $\lambda=0.6328 \mu \mathrm{m}$.

Table IV gives the computed magnitude and phase errors due to ( $+1-\mathrm{nm}, \pm 1-\mathrm{nm})$ thickness errors and $\left(+0.5, \pm 0.5^{\circ}\right)$ angle-of-incidence errors at these angles.
Table III. Summary of Design Results for $\mathrm{MgF}_{2} / \mathrm{Al}$ Polarlzation-Preserving Beam Displacers and Axicons at Three Angles of Incidence ${ }^{*}$

\begin{tabular}{ccccccc}
\hline $\begin{array}{c}\phi \\
\text { (deg) }\end{array}$ & $\zeta_{1}$ & $\zeta_{2}$ & $D_{\phi}(\mu \mathrm{m})$ & $\overline{\mathcal{R}}_{p}$ & $\overline{\mathcal{R}}_{s}$ & $\mathcal{R}_{c}$ \\
\hline 35 & 0.481728 & 0.510810 & 0.25208 & 0.7906 & 0.8546 & 0.7048 \\
45 & 0.430213 & 0.564371 & 0.26693 & 0.7627 & 0.8733 & 0.7133 \\
60 & 0.387927 & 0.611417 & 0.29451 & 0.6896 & 0.9089 & 0.7352 \\
\hline
\end{tabular}

a See text (or footnote to Table I) for explanation of notation.

Table IV. Magnitude and Phase Errors Caused by Introducing (I) FilmThickness Errors $\left(\Delta d_{1}, \Delta d_{2}\right)=(+1, \pm 1) \mathrm{nm}$, (II) Angle-of-Incidence Errors $\left(\Delta \phi_{1}, \Delta \phi_{2}\right)=\left(+0.5, \pm 0.5^{\circ}\right)$ to the Beam Displacer and Axicon Designs of Table III

\begin{tabular}{cccccc}
\hline & $\begin{array}{c}\text { Angle of } \\
\text { incidence } \\
(\phi)\end{array}$ & \multicolumn{2}{c}{$\begin{array}{c}\text { Magnitude error } \\
\left(\left|\rho_{n}\right|-1\right) \times 10^{3}\end{array}$} & \multicolumn{2}{c}{$\begin{array}{c}\text { Phase error } \\
\left(\Delta_{n}\right)(\mathrm{deg})\end{array}$} \\
$\begin{array}{c}\text { Error } \\
\text { type }\end{array}$ & $\begin{array}{c}\text { (deg) } \\
+,-\end{array}$ &,++ &,+- &,++ \\
\hline I & 35 & 0.1055 & -0.4605 & 0.0496 & 0.7412 \\
& 45 & 0.8767 & 0.4743 & 0.3369 & 1.0856 \\
& 60 & 2.528 & 0.0568 & 0.9317 & 1.4810 \\
II & 35 & 0.0694 & 0.2115 & 0.0890 & 0.0718 \\
& 45 & 0.4418 & 0.4489 & -0.6309 & 0.1507 \\
& 60 & 1.1113 & 0.9599 & -1.9322 & 0.30722 \\
\hline
\end{tabular}

\section{Polarization-Preserving Beam Displacers and Axicons at $\lambda=10.6 \mu \mathrm{m}$}

\section{A. ZnS Film on Ag Substrate}

At the IR $\mathrm{CO}_{2}$ laser wavelength $\lambda=10.6 \mu \mathrm{m}, \mathrm{Ag}$ (and likewise for other metals) has a complex refractive index with a large imaginary part and is very highly reflecting. Over most of the angle of incidence range $0<\phi<90^{\circ}$, the $p$ reflectance is only slightly less than the $s$ reflectance, and both reflectances are close to unity. The difference between the $p$ and $s$ reflection phase shifts is also small, so that polarization preservation is approximately satisfied even without dielectric coatings. This is illustrated in Fig. 8, where $\left|\rho_{n}\right|-1$ and $\Delta_{n}$ are plotted vs $\phi . \quad \rho_{n}=\left|\rho_{n}\right| \exp \left(j \Delta_{n}\right)$ is the net ratio of $p$ and $s$ reflection coefficients for two reflections at the same angle from uncoated $\mathrm{Ag}$ surfaces. The magnitude and phase errors increase to unacceptable levels at large angles of incidence approaching $90^{\circ}$.

Dielectric coatings that preserve polarization reduce both the magnitude and phase errors shown in Fig. 8 to zero. The design procedure of Sec. II was applied to a transparent film of $\mathrm{ZnS}\left(N_{1}=2.2\right)$ on $\mathrm{Ag}\left(N_{2}=9.5\right.$ j73). ${ }^{6}$ In this case we found three distinct solutions $\left(\zeta_{1}, \zeta_{2}\right)$ (polarization-correcting normalized film-thickness pairs) for every angle of incidence over the entire range $0<\phi<90^{\circ}$. The three separate solution branches of $\left(\zeta_{1}, \zeta_{2}\right)$ are marked in Fig. 9 as $\left(A_{1}, A_{2}\right)$, $\left(B_{1}, B_{2}\right)$, and $\left(C_{1}, C_{2}\right)$.

In Fig. 10, the net reflectance of the coated device $\mathscr{R}_{c}$ and the net $p$ and $s$ reflectances, $\overline{\mathscr{R}}_{p}$ and $\overline{\mathscr{R}}_{s}$, of the uncoated device are plotted vs $\phi . \mathcal{R}_{c}$ has three branches that correspond to the three solution branches of Fig. 9 and are correspondingly labeled. The differences of $\mathcal{R}_{c}$ among the branches are small, not exceeding $\sim 2 \%$. 


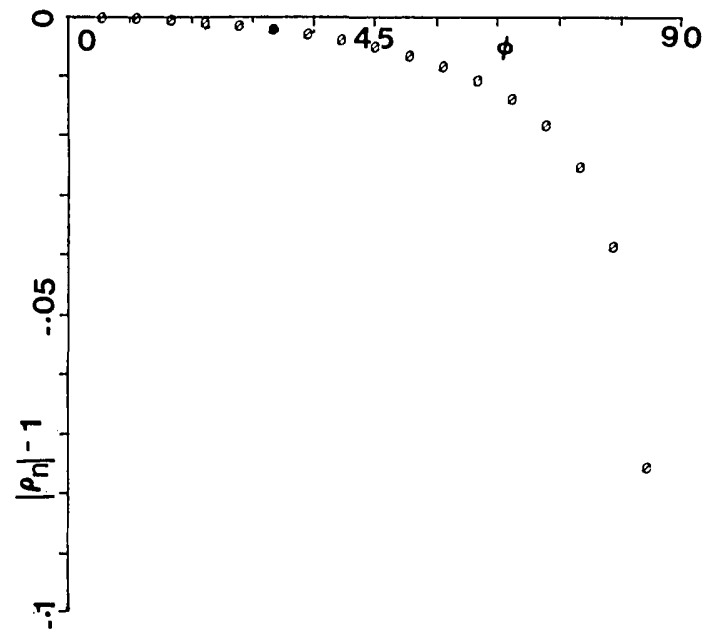

(a)

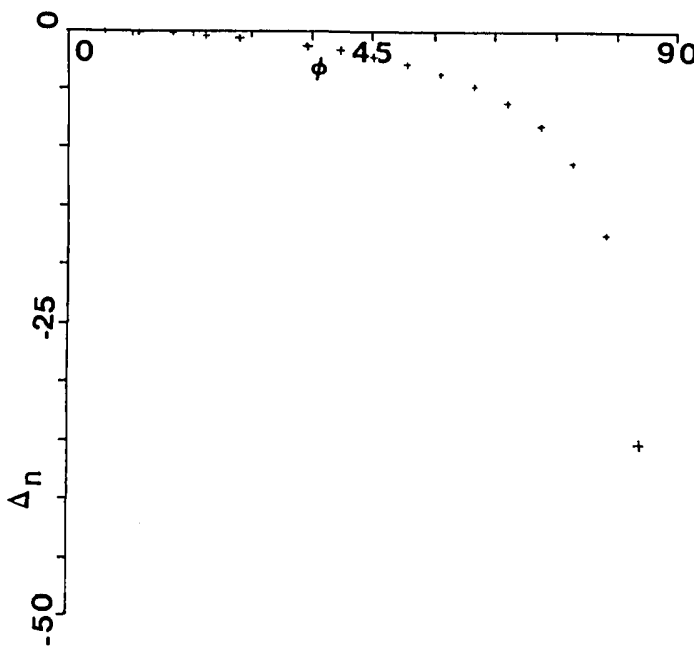

(b)

Fig. 8. Plots of $\left|\rho_{n}\right|-1$ (a) and $\Delta_{n}$ (in deg.) (b) vs angle of incidence $\phi$ for uncoated bare-silver beam displacers and axicons. $\rho_{n}=\left|\rho_{n}\right|$ $\exp \left(j \Delta_{n}\right)$ is the net ratio of complex $p$ and $s$ reflection coefficients for two reflections at the same $\phi$. The complex refractive index of $\mathrm{Ag}$ is taken as $9.5-j 73$ at $\lambda=10.6 \mu \mathrm{m}$.

Table V summarizes design results at $\phi=30,45$, and $60^{\circ}$ of polarization-preserving $\mathrm{ZnS} / \mathrm{Ag}$ beam displacers and axicons for $10.6-\mu \mathrm{m} \mathrm{CO}$ laser radiation.

Table VI documents magnitude and phase errors, caused by $(+1-\mathrm{nm}, \pm 1-\mathrm{nm})$ film-thickness and $\left(+0.5^{\circ}\right.$, $\pm 0.5^{\circ}$ ) angle-of-incidence errors, for all three solutions at each of the angles $\phi=30,45$, and $60^{\circ}$.

\section{B. $\mathrm{ThF}_{4}$ Film on Ag Substrate}

As our final example we take a thorium-fluoride film $\left(N_{1}=1.37\right)^{12}$ on a silver substrate $\left(N_{2}=9.5-j 73\right)$ at $\lambda$ $=10.6 \mu \mathrm{m}$. Figure 11 shows the polarization-correcting normalized film-thickness pair $\left(\zeta_{1}, \zeta_{2}\right)$ as a function of angle of incidence $\phi$. Only one solution per angle exists for $\phi \gtrsim 27^{\circ}$. This result is qualitatively similar to that found for $\mathrm{MgF}_{2}$ on $\mathrm{Al}$ at $0.6328 \mu \mathrm{m}$. It indicates that

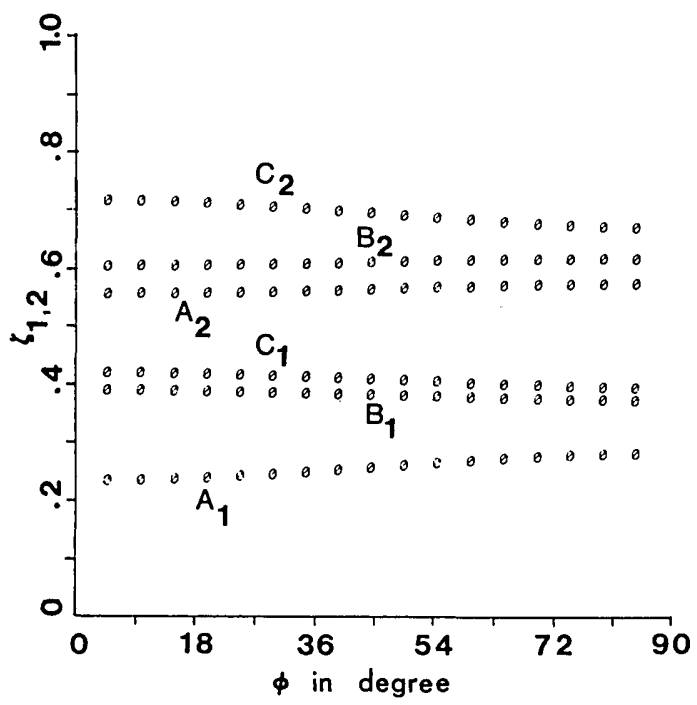

Fig. 9. Normalized film-thickness solution pairs $\left(\zeta_{1}, \zeta_{2}\right)$ that preserve polarization plotted vs angle of incidence $\phi$ for $\mathrm{ZnS} / \mathrm{Ag}$ beam displacers and axicons at $\lambda=10.6 \mu \mathrm{m}$. Three distinct solution branches are indicated by $\left(A_{1}, A_{2}\right),\left(B_{1}, B_{2}\right)$, and $\left(C_{1}, C_{2}\right)$. The refractive indices of $\mathrm{ZnS}$ and $\mathrm{Ag}$ are assumed to be 2.2 and $9.5-j 73$, respectively.

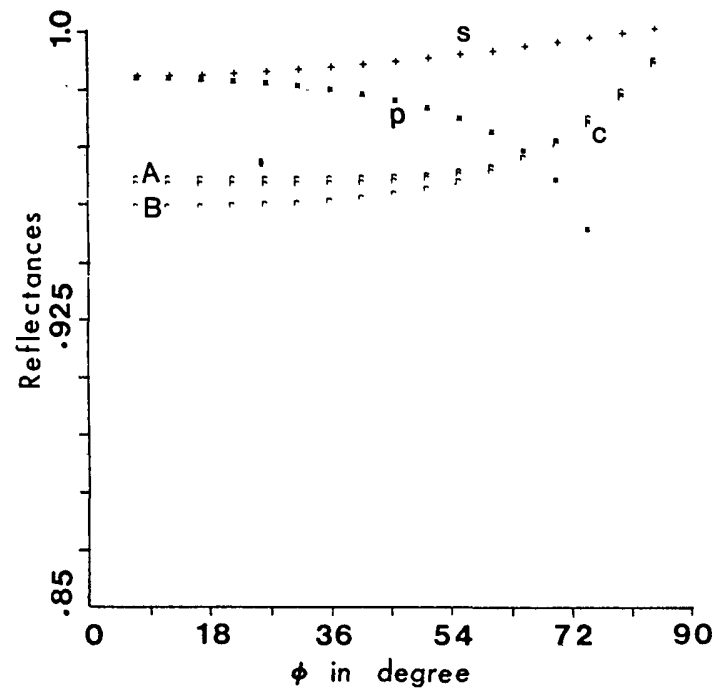

Fig. 10. Reflectances associated with the designs of Fig. 9. Curve $c$ represents the net polarization-independent reflectance of the coated polarization-corrected device, while curves $p$ and $s$ represent the reflectances of the corresponding uncoated device for incident parallel- and perpendicularly polarized light, respectively.

Table V. Summary of Design Results for ZnS/Ag Polarization-Preserving Beam Displacers and Axicons at Three Angles of Incidence. a

\begin{tabular}{cccccccc}
\hline $\begin{array}{c}\phi \\
(\mathrm{deg})\end{array}$ & $\zeta_{1}$ & $\zeta_{2}$ & $D_{\phi}(\mu \mathrm{m})$ & $\overline{\mathcal{R}}_{p}$ & $\overline{\mathcal{R}}_{s}$ & $\mathscr{R}_{c}$ \\
\hline \multirow{4}{*}{30} & $A$ & 0.248008 & 0.563386 & 2.47382 & 0.9839 & 0.9879 & 0.9606 \\
& $B$ & 0.389366 & 0.610939 & 2.47382 & 0.9839 & 0.9879 & 0.9545 \\
& $C$ & 0.418178 & 0.710221 & 2.47382 & 0.9839 & 0.9879 & 0.9593 \\
& $A$ & 0.259708 & 0.568079 & 2.54378 & 0.9804 & 0.9901 & 0.9611 \\
45 & $B$ & 0.385571 & 0.614810 & 2.54378 & 0.9804 & 0.9901 & 0.9568 \\
& $C$ & 0.412711 & 0.699789 & 2.54378 & 0.9804 & 0.9901 & 0.9601 \\
& $A$ & 0.272138 & 0.573447 & 2.62064 & 0.9724 & 0.9930 & 0.9641 \\
60 & $B$ & 0.381525 & 0.618975 & 2.62064 & 0.9724 & 0.9930 & 0.9627 \\
& $C$ & 0.406417 & 0.688617 & 2.62064 & 0.9724 & 0.9930 & 0.9637 \\
\hline
\end{tabular}

a See text (or footnote of Table I) for explanation of notation. 
Table VI. Magnitude and Phase Errors Caused by Introducing (I) FIImThickness Errors $\left(\Delta d_{1}, \Delta d_{2}\right)=(+1, \pm 1) \mathrm{nm}$, (II) Angle-of-Incidence Errors $\left(\Delta \phi_{1}, \Delta \phi_{2}\right)=\left(+0.5, \pm 0.5^{\circ}\right)$ to the Beam Displacer and Axicon Designs of Table V

\begin{tabular}{|c|c|c|c|c|c|}
\hline \multirow{2}{*}{$\begin{array}{c}\text { Type } \\
\text { of } \\
\text { error }\end{array}$} & \multirow{2}{*}{$\begin{array}{c}\text { Angle of } \\
\text { inci- } \\
\text { dence } \\
\phi \\
\text { (deg) }\end{array}$} & \multicolumn{2}{|c|}{$\begin{array}{c}\text { Magnitude } \\
\text { error } \\
\left(\left|\rho_{n}\right|-1\right) \times 10^{4}\end{array}$} & \multicolumn{2}{|c|}{$\begin{array}{c}\text { Phase error } \\
(\text { deg }) \\
\Delta_{n} \times 10\end{array}$} \\
\hline & &,+- &,++ &,+- &,++ \\
\hline I & $\begin{array}{rl} & A \\
30 & B \\
C\end{array}$ & $\begin{array}{l}0.1472 \\
0.2051 \\
0.1552\end{array}$ & $\begin{array}{c}-0.1454 \\
0.02712 \\
0.1406\end{array}$ & $\begin{array}{r}-0.5402 \\
0.0919 \\
0.5156\end{array}$ & $\begin{array}{l}0.2000 \\
0.2338 \\
0.2094\end{array}$ \\
\hline & 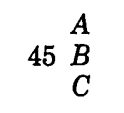 & $\begin{array}{l}0.3619 \\
0.4555 \\
0.3780\end{array}$ & $\begin{array}{r}-0.3335 \\
0.0633 \\
0.3156\end{array}$ & $\begin{array}{l}-1.16 \\
0.2046 \\
1.08\end{array}$ & $\begin{array}{l}0.3939 \\
0.4430 \\
0.4107\end{array}$ \\
\hline & $\begin{array}{rl} & A \\
60 & B \\
C\end{array}$ & $\begin{array}{l}0.6909 \\
0.7210 \\
0.6909\end{array}$ & $\begin{array}{r}-0.5617 \\
0.1077 \\
0.5121\end{array}$ & $\begin{array}{r}-1.8122 \\
0.3284 \\
1.6234 \\
\end{array}$ & $\begin{array}{l}0.5447 \\
0.5711 \\
0.5600 \\
\end{array}$ \\
\hline II & $30 \stackrel{A}{B}$ & $\begin{array}{r}-0.8746 \\
0.1575 \\
0.8465\end{array}$ & $\begin{array}{l}0.0503 \\
0.0597 \\
0.0537\end{array}$ & $\begin{array}{l}-7.597 \\
-9.327 \\
-8.021\end{array}$ & $\begin{array}{l}0.0224 \\
0.0259 \\
0.0230\end{array}$ \\
\hline & $\begin{array}{rl} & A \\
45 & B \\
C\end{array}$ & $\begin{array}{r}-1.3839 \\
0.2457 \\
1.2966\end{array}$ & $\begin{array}{l}0.1429 \\
0.1627 \\
0.1528\end{array}$ & $\begin{array}{l}-14.33 \\
-14.94 \\
-16.66\end{array}$ & $\begin{array}{l}0.0645 \\
0.0717 \\
0.0660\end{array}$ \\
\hline & $\begin{array}{rl} & A \\
60 & B \\
C\end{array}$ & $\begin{array}{r}-1.3388 \\
0.2078 \\
1.1549\end{array}$ & $\begin{array}{l}0.2299 \\
0.2433 \\
0.2440\end{array}$ & $\begin{array}{l}-25.42 \\
-27.13 \\
-25.93\end{array}$ & $\begin{array}{l}0.1034 \\
0.1064 \\
0.1036\end{array}$ \\
\hline
\end{tabular}

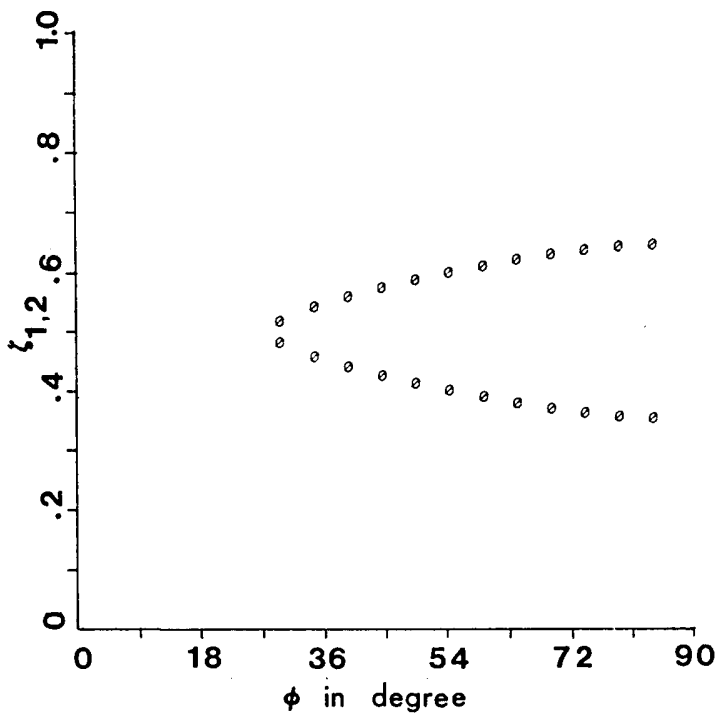

Fig. 11. Normalized film-thickness solution pair $\left(\zeta_{1}, \zeta_{2}\right)$ that preserves polarization plotted vs angle of incidence $\phi$ for $\mathrm{ThF}_{4} / \mathrm{Ag}$ beam displacers and axicons at $\lambda=10.6 \mu \mathrm{m}$. The refractive indices of $\mathrm{ThF}_{4}$ and $\mathrm{Ag}$ are taken as 1.37 and $9.5-j 73$, respectively.

the film refractive index plays the dominant role in specifying the nature of possible design solutions $\left(\zeta_{1}, \zeta_{2}\right)$.

Figure 12 gives the reflectance $\mathcal{R}_{c}$ of the coated device and $\overline{\mathcal{R}}_{p}$ and $\overline{\mathcal{R}}_{s}$ for the device without films. Notice that over the entire range of angles $\phi \gtrsim 27^{\circ}$ where polarization correction is possible, the net reflectance $\mathcal{R}_{c}$ is over $96 \%$. Notice also that $\mathscr{R}_{c}$ exceeds $\overline{\mathscr{R}}_{p}$ for $\phi \gtrsim$ $55^{\circ}$; i.e., the reflectance is higher with polarizationcorrective films than it is for the uncoated device with incident $p$-polarized light.

Table VII summarizes the design data of polarization-preserving $\mathrm{ThF}_{4} / \mathrm{Ag}$ beam displacers and axicons for $10.6-\mu \mathrm{m} \mathrm{CO} 2$ laser radiation at angles of incidence $\phi=30,45$, and $60^{\circ}$. Table VIII gives the associated magnitude and phase errors caused by (+1-nm, $\pm 1-\mathrm{nm})$ thickness errors and $\left(+0.5^{\circ}, \pm 0.5^{\circ}\right)$ angle-of-incidence errors.

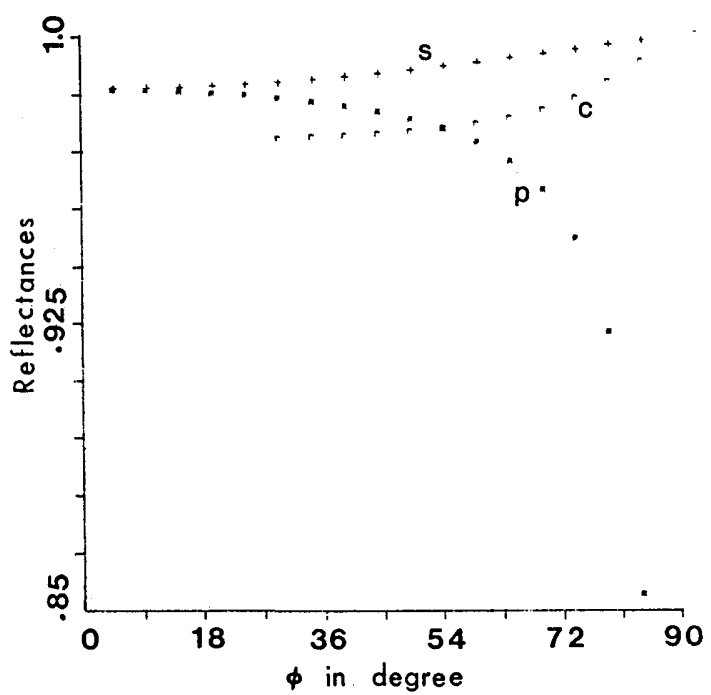

Fig. 12. Reflectances associated with the designs of Fig. 11. Curve $c$ represents the net polarization-independent reflectance of the coated (polarization-corrected) device, while $p$ and $s$ represent the reflectances of the corresponding uncoated device for incident parallel- and perpendicularly polarized light, respectively.

Table VII. Summary of Design Data for $\mathrm{ThF}_{4}$-Ag Polarization-Preserving Beam Displacers and Axicons at Three Angles of Incidence ${ }^{2}$

\begin{tabular}{ccccccc}
\hline $\begin{array}{c}\phi \\
(\mathrm{deg})\end{array}$ & $\zeta_{1}$ & $\zeta_{2}$ & $D_{\phi}(\mu \mathrm{m})$ & $\overline{\mathcal{R}}_{p}$ & $\overline{\mathcal{R}}_{s}$ & $\mathcal{R}_{c}$ \\
\hline 30 & 0.482391 & 0.517601 & 4.15523 & 0.9839 & 0.9879 & 0.9741 \\
45 & 0.426483 & 0.573512 & 4.51509 & 0.9804 & 0.9901 & 0.9753 \\
60 & 0.389570 & 0.610428 & 4.99245 & 0.9724 & 0.9930 & 0.9778 \\
\hline
\end{tabular}

a See text (or footnote of Table I) for explanation of notation.

Table VIII. Magnitude and Phase Errors Caused by Introducing (I) FilmThickness Errors $\left(\Delta d_{1}, \Delta d_{2}\right)=(+1, \pm 1) \mathrm{nm}$, (II) Angle-of-Incidence Errors $\left(\Delta \phi_{1}, \Delta \phi_{2}\right)=\left(0.5, \pm 0.5^{\circ}\right)$ to Beam Displacer and Axicon Designs of Table VII

\begin{tabular}{cccccc}
\hline $\begin{array}{c}\text { Type } \\
\text { of } \\
\text { error }\end{array}$ & $\begin{array}{c}\text { Angle of } \\
\text { incidence } \\
(\phi) \\
(\mathrm{deg})\end{array}$ & \multicolumn{2}{c}{$\begin{array}{c}\text { Magnitude error } \\
\left(\left|\rho_{n}\right|-1\right) \times 10^{6}\end{array}$} & \multicolumn{2}{c}{$\begin{array}{c}\text { Phase error } \\
\left(\Delta_{n} \text { in deg) }\right.\end{array}$} \\
\hline I & 30 & 0.5513 & -0.1490 & 0.0002 & 0.0338 \\
& 45 & 5.1550 & -0.1639 & 0.0022 & 0.0645 \\
& 60 & 12.25 & 0.0894 & 0.0054 & 0.0870 \\
II & 30 & 0.0440 & 9.8190 & -0.0941 & 0.0043 \\
& 45 & 4.6190 & 33.190 & -0.7465 & 0.0145 \\
& 60 & 9.089 & 67.70 & -2.0816 & 0.0298 \\
\hline
\end{tabular}




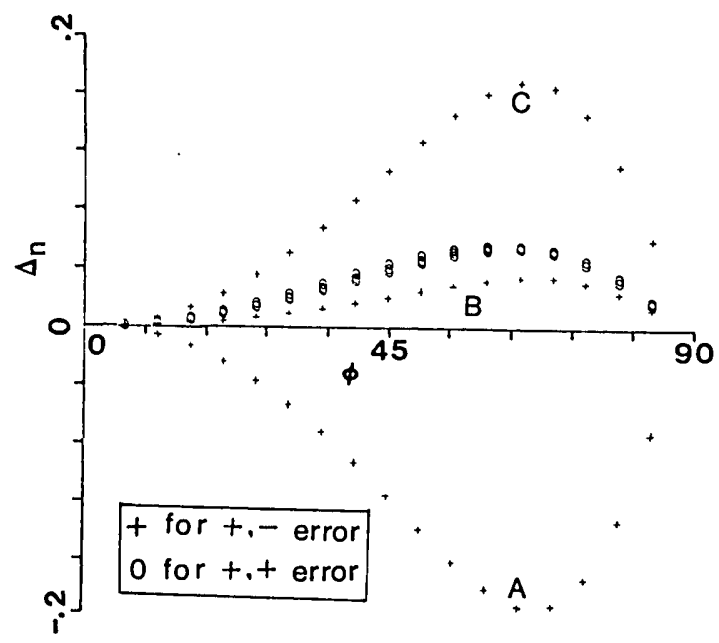

Fig. 13. Phase errors (in degrees) caused by introducing simultaneous film-thickness errors of $\left(\Delta d_{1}, \Delta d_{2}\right)=(+1 \mathrm{~nm}, \pm 1 \mathrm{~nm})$ to the design data of Fig. 9 for the $\mathrm{ZnS} / \mathrm{Ag}$ system at $10.6 \mu \mathrm{m}$. Branch identification is the same as that used in Fig. 9.

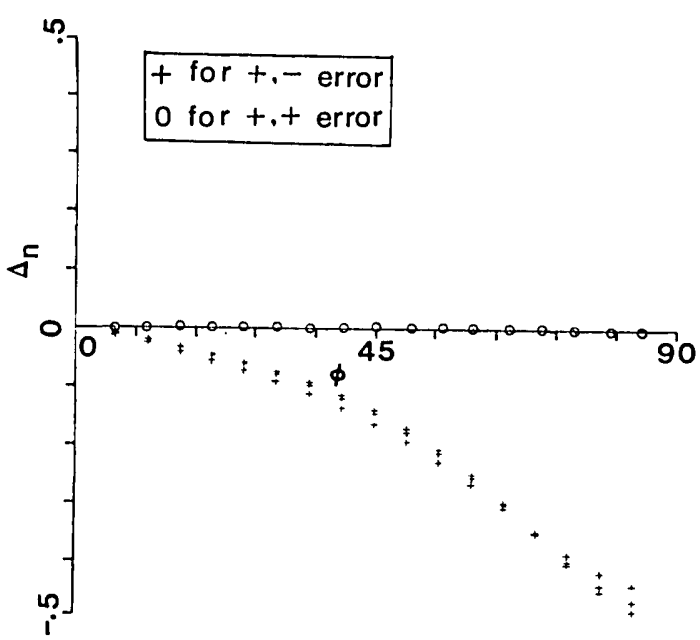

Fig. 14. Same as in Fig. 13 for assumed simultaneous angle-of-incidence errors of $\left(\Delta \phi_{1}, \Delta \phi_{2}\right)=\left(+0.5^{\circ}, \pm 0.5^{\circ}\right)$. The film thicknesses are left equal to their correct design values.

\section{v. Summary}

In this paper we have described in detail a procedure for the design of single-layer-coated polarization-preserving parallel-mirror beam displacers and axicons. The method has been applied to two film-substrate systems, $\mathrm{Al}_{2} \mathrm{O}_{3}$ or $\mathrm{Si}_{2} \mathrm{O}_{3} / \mathrm{Al}$ and $\mathrm{MgF}_{2} / \mathrm{Al}$, for $\mathrm{He}-\mathrm{Ne}$ laser light $(\lambda=0.6328 \mu \mathrm{m})$ and to two others, $\mathrm{ZnS} / \mathrm{Ag}$ and $\mathrm{ThF}_{4} / \mathrm{Ag}$, for $\mathrm{CO}_{2}$ laser light $(\lambda=10.6 \mu \mathrm{m})$. Results have been documented both graphically and in tables.

This work served as part of the M.Sc. thesis submitted by E. M. R. Khan to the Graduate School of the University of New Orleans.

R. M. A. Azzam is pleased to acknowledge support by the National Science Foundation under grant DMR8018417.

\section{Appendix: Remarks on Design Sensitivity}

For \pm 1 -nm thickness errors and $\pm 0.5^{\circ}$ angle-of-incidence errors, the $(--)$ and $(-+)$ error combinations yield results of nearly the same magnitude as and of opposite sign to those obtained for the $(++)$ and $(+-)$ error combinations (given in the tables), respectively, at all angles of incidence. This is expected for small errors from first-order analysis.

Errors increase with angle of incidence reaching, in most cases, a peak near (but downshifted from) the pseudo-Brewster angle of the substrate.

For a given $\Delta d$ (e.g., $\pm 1 \mathrm{~nm})$ at a given $\phi$ the magnitude and phase errors decrease with increase of wavelength (they are less at $10.6 \mu \mathrm{m}$ than at $0.6328 \mu \mathrm{m}$ ) because of the larger film-thickness period $D_{\phi}$, hence the smaller normalized-thickness error $\Delta \zeta=\Delta d / D_{\phi}$.

We have verified that magnitude and phase errors vary essentially linearly with $\Delta d$ up to $\pm 5 \mathrm{~nm}$ and with $\Delta \phi$ up to $\pm 2.5^{\circ}\left(\right.$ at $\left.\phi=45^{\circ}\right)$. However, we encountered one exception, namely, the phase error caused by opposite-sign $\Delta d$ errors for the $\mathrm{Al}_{2} \mathrm{O}_{3}\left(\mathrm{Si}_{2} \mathrm{O}_{3}\right) / \mathrm{Al}$ system.

For illustration, Fig. 13 shows the phase errors caused by thickness errors $\left(\Delta d_{1}, \Delta d_{2}\right)=(+1 \mathrm{~nm}, \pm 1 \mathrm{~nm})$ plotted vs angle of incidence $\phi$ for the three solution branches $(A, B$, and $C)$ obtained for the $\mathrm{ZnS} / \mathrm{Ag}$ system at $\lambda=10.6 \mu \mathrm{m}$. Figure 14 gives the corresponding phase errors caused by angle-of-incidence errors $\left(\Delta \phi_{1}\right.$, $\left.\Delta \phi_{2}\right)=\left(+0.5^{\circ}, \pm 0.5^{\circ}\right)$ plotted vs $\phi$ for the same system. Note that solution branch $B$ is least susceptible to error.

Similar magnitude- and phase-error curves are available for all other systems and are not included here for brevity.

\section{References}

1. R. M. A. Azzam, Opt. Lett. 7, 80 (1982).

2. L. W. Casperson and M. S. Shekhani, Appl. Opt. 14, 2653 (1975).

3. R. A. Chodzko, S. B. Mason, and E. F. Cross, Appl. Opt. 15, 2137 (1976).

4. P. B. Mumola, H. J. Robertson, G. N. Steinberg, J. L. Kreuzer, and A. W. McCullough, Appl. Opt. 17, 936 (1978).

5. D. Fink, Appl. Opt. 18, 581 (1979).

6. W. H. Southwell, Appl. Opt. 18, 1875 (1979).

7. See, for example, R. M. A. Azzam and N. M. Bashara, Ellipsometry and Polarized Light (North-Holland, Amsterdam, 1977), Sec. 4.3.

8. See, for example, G. W. Stagg and A. H. El-Abiad, Computer Methods in Power System Analysis (McGraw-Hill, New York, 1968), p. 249.

9. G. Hass, in Applied Optics and Optical Engineering, R. Kingslake, Ed. (Academic, New York, 1965), Vol. 3, Chap. 8.

10. Interpolated from values given by G. Hass and J. E. Waylonis, J. Opt. Soc. Am. 51, 7 (1961); See T. H. Allen, J. Vac. Sci. Technol. 13,112 (1976).

11. See, for example, O. S. Heavens, Optical Properties of Thin Solid Films (Dover, New York, 1965).

12. M. E. Pedinoff, M. Braunstein, and O. M. Stafsudd, in Optical Polarimetry, R. M. A. Azzam and D. L. Coffeen, Eds., Proc. Soc. Photo-Opt. Instrum. Eng. 112, 74 (1977). 